Special Issue of the 6th International Congress \& Exhibition (APMAS2016), Maslak, Istanbul, Turkey, June 1-3, 2016

\title{
Investigation into the Surface Properties of Papers Sized with Styrene-Acrylate-Cationic Monomer Based Terpolymers
}

\author{
M. ÖZDEMIR ${ }^{a}$, A. AYTAÇ ${ }^{a, b, *}$ AND V. Deniz ${ }^{a, b}$ \\ ${ }^{a}$ University of Kocaeli, Department of Polymer Science and Technology, 41380 Kocaeli, Turkey \\ ${ }^{b}$ University of Kocaeli, Department of Chemical Engineering, 41380 Kocaeli, Turkey
}

In this study, styrene(St)/2-ethyl hexyl acrylate(2-EHA) based surface sizing materials were developed with four different cationic monomers (CM), namely diallyldimethyl ammonium chloride (DADMAC), [2-(methacryloyloxy) ethyl] trimethylammonium chloride (MATMAC), [3-(methacryloylamino) propyl]-trimethyl ammonium chloride (MAPTAC), (viniylbenzyl) trimethyl-ammonium chloride (VBTMAC). Ternary polymerization was realized with emulsion polymerization, by using 2,2'-azobis (2-methylpropionamidine) dihydrochloride (A) as initiator. Thermal properties of the synthesized terpolymers were determined with differential scanning calorimeter and thermal gravimetric analysis. Differential scanning calorimeter results showed that glass transition temperature $\left(T_{g}\right)$ values of polymers were not dependent on the types of cationic monomers, and were found about $44-45^{\circ} \mathrm{C}$. Ion exchange capacities of the terpolymers were determined. The latexes produced were used as sizing materials for paper surface treatment. Then critical surface properties of the papers sized such as water resistance (Cobb value) and contact angle were measured. It was found that the best, i.e. the lowest Cobb results were obtained when MATMAC and MAPTAC cationic monomers were used in terpolymers.

DOI: 10.12693/APhysPolA.131.178

PACS/topics: $68.47 . P e, 82.35 .-\mathrm{x}$

\section{Introduction}

Paper fibers, which are consisting of cellulose, have a strong natural tendency to absorb the liquids. End users of paper productions have the demands of paper resistance to diffusion and absorption of liquids. Surface treatments such as sizing are usually used in paper industry to increase the barrier properties of paper to the liquids. Polymer barrier sized papers, such as copolymers of styrene, urethane and acrylamide can improve the water resistance of paper by forming a layer of polymer film on the top of the paper surface. Polymer latexes are widely used in various industries, such as paints, coatings, and paper industries. These latexes can be added to the paper to provide excellent liquid resistance. However, the effectiveness of these polymeric materials cannot fully satisfy the papermaker's requirements $[1,2]$. For this reason, investigation on the polymeric sizing materials by using different materials and synthesis conditions increasingly continues. For example, Wang et al. reported the novel surface sizing agent which is modified with the collagen for paper industry. Their result showed that the tensile strength of the paper increased by using collagen modified styrene acrylate based sizing agent [3]. In addition to this, styrene-acrylate emulsions with anionic, cationic or nonionic characters can be synthesized depending on the chemical structure of emulsifier [4]. Latex particles whose surface is positively charged by using cationic monomers are also required in many cases of paper industries $[1,2]$. Wu et al. showed that the cationic

*corresponding author; e-mail: aaytac@kocaeli.edu.tr styrene-acrylic acid ester emulsion (SAE) provided the higher surface strength and lower Cobb value than the paper sized with other surface sizing agents such as anionic SAE and oxidized starch [5]. Studies on cationic latexes clearly fall behind their industrial demands and there are less report relatively compared to anionic latexes. The cationic nature enables polymer to adhere to and diffuse on the paper surface easily and efficiently. Cationic latexes such as polyvinyl alcohol, cationically charged polystyrene latexes and a polystyrene based copolymer provide excellent water resistance. Recent studies showed that latexes could coat uniformly occurred surfaces of fibers in paper, which resulted in higher resistance to water penetration [6].

In this study, styrene(St)/2-ethyl hexyl acrylate(2EHA) based surface sizing materials were developed with four different cationic monomers $(\mathrm{CM})$. Ternary polymerization was performed with emulsion polymerization to investigate the effect of cationic monomers types on the performance of the surface sizing materials. For this purpose, contact angle measurements, the Cobb test, ion exchange capacity, the Fourier transform infrared (FTIR), differential scanning calorimeter (DSC), thermal gravimetric analysis (TGA), and scanning electron microscopy (SEM) analysis were performed.

\section{Material and equipment}

In the experimental work, St, 2-EHA, DADMAC, MATMAC, MAPTAC, and VBTMAC were used as monomers, A was used as initiator and acetic acid was used for $\mathrm{pH}$ adjustment. Monomers for emulsion polymerization were provided from Soditaş (Turkey). The initiator, emulsifier and acetic acid were obtained from Ak-Kim (Turkey). 


\subsection{The synthesis of terpolymers by emulsion polymerization}

Terpolymers which were called as St/2-EHA/cationic monomer were synthesized by using the emulsion polymerization. In this polymerization system, the ethoxylated amine type emulsifier was used. The emulsifier was added by weight of total amount of monomer system at $7 \mathrm{wt} \%$ rate. Compound A was charged as initiator and all the other parameters were held constant. Four terpolymer samples and one copolymer as control samples were synthesized in this manner. The polymerization reactions were performed in a temperature controlled glass polymerization reactor system with nitrogen gas inlet and outlet. For the production of polymers by emulsion polymerization, the initiator $(1 \mathrm{wt} \%$ of the total amount of the monomer) was added into deionized water. The polymerization flask was purged of oxygen during the reaction by passing nitrogen gas. Intent to pre-emulsion preparation in another beaker with water and emulsifier by using $70 \%$ styrene, $25 \%$ acrylate, $5 \%$ cationic monomer for terpolymers and for copolymer of control sample (WCM) by using $70 \%$ styrene, $30 \%$ acrylate at stoichiometric ratios were prepared at first. The $\mathrm{pH}$ value was set to be in the range of 2 to 3 with acetic acid. When the polymerization temperature in the reactor reached $70^{\circ} \mathrm{C}$, pre-emulsion was added slowly to the reaction medium. After completing the addition of pre-emulsion, the reaction was carried out at constant mixing speed of $750 \mathrm{rpm}$ for $4 \mathrm{~h}$.

\subsection{Sizing process}

Papers to be used for sizing process were produced by using Estanit $(\mathrm{GmbH})$ paper machine. Produced papers were coated by using Mathis SVA-IR-B 605 size press with the synthesized copolymers and terpolymers. The equal amount of sizing solution was applied to the surface of prepared paper. Sized paper were then dried at $105^{\circ} \mathrm{C}$.

\subsection{Analysis applied to the terpolymer samples and the sized paper}

FTIR analyses were performed to determine polymers' structure. Each sample was analysed after drying in an oven at $105^{\circ} \mathrm{C}$ for $2 \mathrm{~h}$. ATR Thermo Scientific Nicolet FTIR instrument was used for analyses. DSC analysis was performed using Mettler Toledo Star System equipment DSC1. During thermal analysis, $10^{\circ} \mathrm{C} / \mathrm{min}$ heating rate was applied to samples. Analysis of all samples was carried out in the temperature range of -50 and $180^{\circ} \mathrm{C}$. TGA was carried out with a Mettler TGA-1 instrument. Samples were heated from $30^{\circ} \mathrm{C}$ to $600^{\circ} \mathrm{C}$ at a heating rate of $10^{\circ} \mathrm{C} / \mathrm{min}$ under $\mathrm{N}_{2}$ atmosphere. In order to determine ionic character of polymer samples, a Mutec-PCD 03 brand analyzer particle charge detector was used. Automatic titration was performed by using PES-Na solution and ionic consumption was recorded, and then ion exchange capacity was calculated. Particle size (hydrodynamic radius) and polydispersity index
(PDI) were measured using an ALV/CGS-3 compact goniometer system (Malvern, UK).

The Cobb test is a simple technique for measurement of water absorbancy of paper. The Cobb value is defined as the mass of water absorbed in a specific time by 1 square meter of paper, board or corrugated fiber board under $1 \mathrm{~cm}$ of water in $60 \mathrm{~s}$. The Cobb measurements were made according to Technological Association of the Pulp and Paper Industry (TAPPI) standard T-441. The contact angle measurements were performed by using the Theta Lite device. Distilled water was used in this measurement. Surface morphologies of the sized papers were examined by SEM (JEOL JSM6335-F). Before the examinations, the surfaces of the papers were sputter coated with gold in order to prevent arcing.

\section{Results and discussion}

FTIR analysis was performed to determine the structural analysis of the terpolymer samples. Specific absorption peaks of terpolymers were given in Fig. 1. The bands at $3027 \mathrm{~cm}^{-1}$ could be assigned to the characteristic vibration peaks of phenyl ring in Fig. 1. Also, deformation, and vibration peaks were observed at 1600 and $695 \mathrm{~cm}^{-1}$ of the phenyl group in the St. These peaks clearly were shown by the formation of terpolymer [7]. Besides, all of the typical bands due to St, which were located at approximately 1600,750 , and $700 \mathrm{~cm}^{-1}$ and the peak at $1728 \mathrm{~cm}^{-1}$ correspond to the $\mathrm{C}=\mathrm{O}$ group of 2-EHA [8].

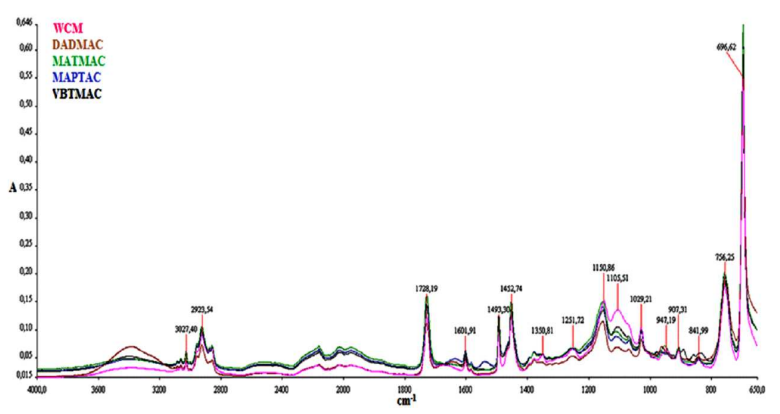

Fig. 1. FTIR spectra of terpolymers and WC.

Characteristic properties of the synthesized terpolymers and WCM were given in Table I. Only one glass transition temperature $\left(T_{g}\right)$ was observed for all the samples on DSC analysis. $T_{g}$ values of poly $(2-\mathrm{EHA})$ and polystyrene appear as -55 and $100^{\circ} \mathrm{C}$, respectively. It was found that the $T_{g}$ values for the synthesized terpolymers were situated between these two values. The $T_{g}$ values of terpolymers were observed between $45.2^{\circ} \mathrm{C}$ and $44.4^{\circ} \mathrm{C}$. In addition to this, the $T_{g}$ values increased with the cationic monomers loading. The particle radius values of terpolymers and WCM were given in Table I. It was found that the radius of the particles was less than $100 \mathrm{~nm}$. The results show that the average diameters of terpolymers' particles were found to be in the range of $43.4-52.6 \mathrm{~nm}$ which were greater than $36 \mathrm{~nm}$ of average 
diameters of WCMs' particles. The particle of terpolymers and WCMs' PDI had changed between 0.13 and 0.07 in emulsion. To be monodisperse distribution, PDI value should be smaller than one which was indicated in all samples and was obtained monodisperse distribution for particle size except for MAPTAC. Also wider distribution was obtained with terpolymers than in WCM. Solid contents, $\mathrm{pH}$ values, and ionic properties of synthesized copolymers were also measured. The solid contents of terpolymers changed between $40.8 \mathrm{wt} \%$ and $53.5 \mathrm{wt} \%$. It was determined that the $\mathrm{pH}$ values changed from 3.5 to 3.4. According to the ion exchange capacity analysis, cationic type's terpolymers were obtained in all terpolymer samples. Ion exchange capacities of terpolymers were obtained 10 times higher compared to the WCM sample. The highest ion exchange capacity was seen by using MAPTAC.

TABLE I

Characteristic properties of the synthesized copolymer and terpolymers.

\begin{tabular}{|c|c|c|c|c|c|}
\hline & $\begin{array}{l}\sum_{i} \\
3\end{array}$ & 岁 & 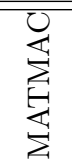 & 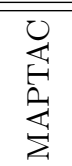 & 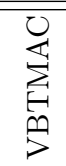 \\
\hline $\mathrm{pH}$ & 3.5 & 3.4 & 3.5 & 3.4 & 3.4 \\
\hline $\begin{array}{l}\text { solid content [\%] } \\
\text { ion exchange }\end{array}$ & 33.7 & 53.5 & 41.5 & 40.8 & 51.3 \\
\hline capacity $[\mathrm{meq} / \mathrm{g}]$ & 0.05 & 0.40 & 0.53 & 0.58 & 0.50 \\
\hline$T_{g}\left[{ }^{\circ} \mathrm{C}\right]$ & 40.3 & 45.2 & 44.4 & 44.5 & 44.4 \\
\hline radius $[\mathrm{nm}]$ & 36 & 48 & 52.6 & 43.4 & 50.3 \\
\hline PDI & 0.07 & 0.06 & 0.06 & 0.13 & 0.1 \\
\hline
\end{tabular}

TGA analysis was performed to define the thermal stability of the synthesized terpolymers. Two-stage decomposition was observed; firstly, copolymers or terpolymers lose water and then at the second stage copolymers degrade. The solid content of terpolymers can be estimated by TGA curves given in Fig. 2 .

Contact angle and the Cobb values of the terpolymers and WCM samples were given in Table II. The contact

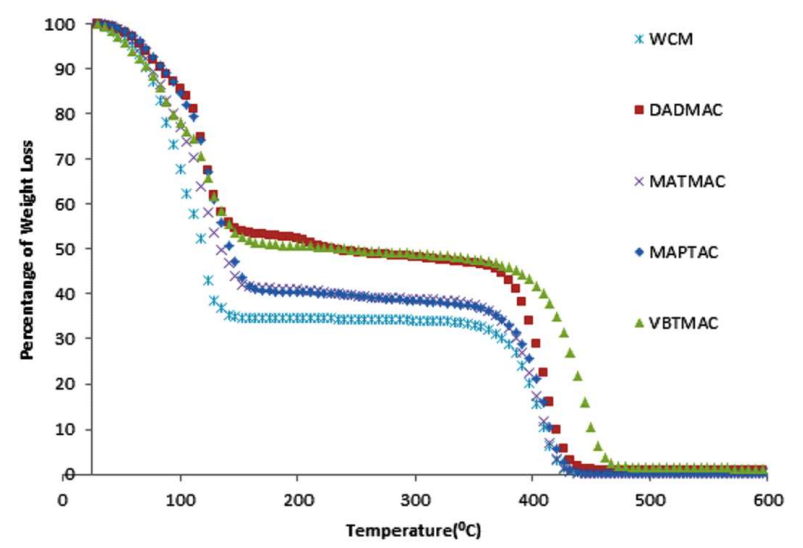

Fig. 2. TGA curves of the terpolymers and WCM. angle values of terpolymers were less than $90^{\circ}$ except for WCM. The polymers having contact angle less than $90^{\circ}$ are characterized as hydrophilic in the literature. Water resistance of paper decreased with the increase of their Cobb values. The lowest Cobb values were obtained for MATMAC and MAPTAC cationic monomers. This case was confirmed also with the results of high ion exchange capacity. The Cobb value of untreated papers was measured as $254 \mathrm{~g} / \mathrm{m}^{2}$. The Cobb measurements showed that water resistances of sized papers were improved by $300 \%$ compared to the untreated paper.

TABLE II

Cobb and contact angle values of the sized papers.

\begin{tabular}{c|c|c}
\hline \hline & Contact angle $\left[{ }^{\circ}\right]$ & Cobb $\left[\mathrm{g} / \mathrm{m}^{2}\right]$ \\
\hline untreated paper & - & 254 \\
WCM & 105.8 & 111 \\
DADMAC & 73.6 & 106 \\
MATMAC & 81.8 & 74 \\
MAPTAC & 76.6 & 75 \\
VBTMAC & 58.3 & 112
\end{tabular}

The surface morphologies of the sized and untreated papers were investigated by SEM. The SEM images were given in Fig. 3a-f respectively. A fibrous structure was clearly observed for the untreated paper surface in Fig. 3a. On the other hand, it was observed that the sized paper surface loses the fibrous structure especially on VBTMAC sample (Fig. 3f).

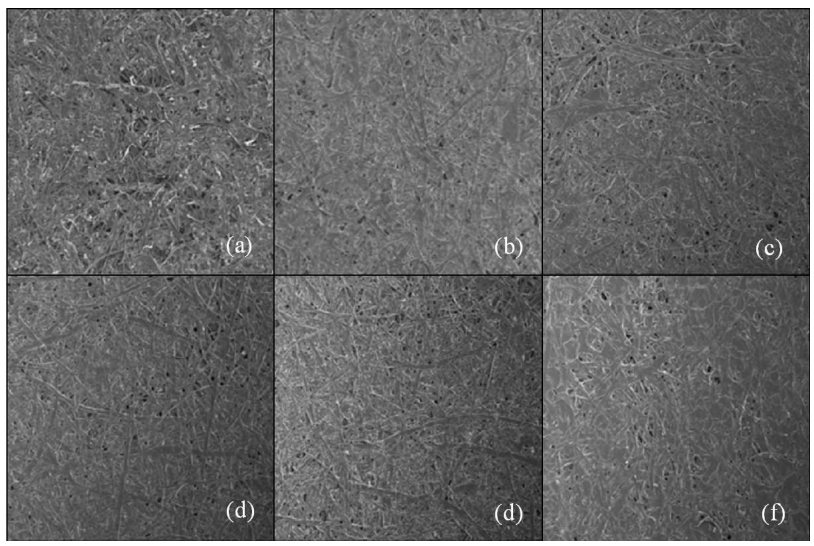

Fig. 3. SEM images of paper surface: (a) untreated paper, (b) sized with WCM, (c) sized with DADMAC, (d) sized with MATMAC, (e) sized with MAPTAC, (f) sized with VBTMAC.

\section{Conclusion}

In this study, the effects of cationic monomer types on the performance of the surface sizing materials were investigated. Cationic type terpolymers were obtained in all cases. The formations of copolymers were verified by FTIR measurements. Only one glass transition temperature was observed for all synthesized samples by DSC 
analysis. $T_{g}$ values of copolymers were observed between 45.2 and $44.4^{\circ} \mathrm{C}$. The average diameter of terpolymers particles were found to be in the range of 43.4-52.6 nm which were more than $36 \mathrm{~nm}$ of average diameters of WCMs' particles. In all samples there was obtained monodisperse distribution for particle size except for MAP$\mathrm{TAC}$ including terpolymer. Ion exchange capacities of terpolymers were found to be 10 times higher than WCM sample. The highest ion exchange capacity was obtained with MAPTAC. According to the SEM analysis, the sized paper surface loses the fibrous structure especially for VBTMAC sample. The lowest $C$ values were obtained with MATMAC and MAPTAC cationic monomers.

\section{Acknowledgments}

This study was supported by Ministry of Science, Industry and Technology of Turkey under the Project number 0011.STZ.2013-1.

\section{References}

[1] Y. Yang, L. Zhang, X. Zhu, X. Kong, J. Appl. Polym. Sci. 124, 3662 (2012).

[2] Z. Liu, H. Xiao, N. Wiseman, J. Appl. Polym. Sci. 76, 1129 (2000)

[3] X. Wang, X. Hao, L. Ren, T. Qiang, S. Zhang, BioResources 9, 1255 (2014).

[4] A.M. Santos, F.M.B. Coutinho, Polym. Bull. 30, 407 (1993).

[5] X. Wu, Y. Cui, Y. Jinga, J. Mosseler, J. Bioresourc. Bioprod. 1, 36 (2016).

[6] X. Yan, Y. Ji, T. Heb, Progr. Org. Coat. 76, 11 (2013).

[7] W. Wang, Q. Zhang, F. Guo, J. Gu, C. Yin, J. Polym. Res. 18, 1229 (2011).

[8] H. Hua, M.A. Dubé, Polym.-Plast. Technol. Eng. 50, 349 (2011). 